\title{
Multi-drug resistance and molecular pattern of erythromycin and penicillin resistance genes in Streptococcus pneumoniae
}

\author{
Mohammad Kargar $^{1 *}$, Maryam Baghernejad ${ }^{1}$, Sadegh Ghorbani-Dalini ${ }^{2}$ and Akram Najafi ${ }^{1}$ \\ ${ }^{1}$ Department of Microbiology, Jahrom Branch, Islamic Azad University, Jahrom, Iran. \\ ${ }^{2}$ Department of Microbiology, Jahrom Branch, Young Researcher's Club, Islamic Azad University, Jahrom, Iran.
}

Accepted 23 November, 2011

The appearance and dissemination of penicillin resistant and macrolide resistant Streptococcus pneumoniae strains has caused increasing concern worldwide. The aim of this study was to survey drug resistance and genetic characteristics of macrolide and penicillin resistance in S. pneumoniae. This is a cross-sectional study, which was carried out on 70 samples suspected to be $S$. pneumoniae isolated from patients who were admitted in Intensive Care Unit (ICU) of southwest of Iran, in 2010 and 2011. At first, suspected colonies were identified by phenotypic and chemical tests. The isolates were confirmed as S. pneumoniae based on the presence of lytA gene by polymerase chain reaction (PCR) method. Antibiotic resistance was evaluated according to Standard Clinical and Laboratory Standards Institute (CLSI). Minimum inhibitory concentrations (MICs) of erythromycin and penicillin were determined by the E-test method. Molecular analyses of macrolide and penicillin resistance were carried out by using specific primers for detection of the resistance gene including erm(B), mef(A), pbp1a, pbp2b and pbp2x genes. The lytA gene was detected in 50 samples. There was prevalence of resistant strains to erythromycin $(56 \%)$, penicillin $(40 \%)$, ampicillin $(56 \%)$, cefotaxime $(50 \%)$, tetracycline $(10 \%)$, trimethoprim-sulfamethoxazole $(48 \%)$, nalidixic acid $(16 \%)$, clarithromycin $(48 \%)$, azithromycin $(44 \%)$ and levofloxacin (4\%). All strains were susceptible to chloramphenicol, amikacin, streptomycin and gentamicin. Gene analysis showed that 29 strains $(58 \%)$ had $\operatorname{mef}(A)$ gene, and 24 strains $(48 \%)$ had the $\operatorname{erm}(B)$ gene. Out of all the penicillin resistance and intermediate strains, $6(20 \%)$ and $1(3.33 \%)$ strains harbor mutations in pbp1a and pbp2x genes, respectively, but pbp2b was not identified in any sample. Resistance to penicillin, trimethoprim-sulfamethoxazole, clarithromycin and azithromycin in $S$. pneumoniae is a serious problem in this area and the local pattern of resistance/susceptibility must be considered for therapeutic regimens. The $\operatorname{mef}(A)$ gene was a predominant mechanism of macrolide resistance in this area. With regards to low frequency of pbps resistance genes, monitoring of other kinds of mechanisms is recommended.

Key words: Streptococcus pneumoniae, multi-drug resistance, erythromycin, penicillin, resistance genes.

\section{INTRODUCTION}

As a major bacterial pathogen, Streptococcus pneumonia infection starts from colonization of the human upper

\footnotetext{
*Corresponding author. Email: mkargar@jia.ac.ir. Tel: +989173149203 Fax: +98711- 6262102
}

Abbreviations: ICU, Intensive Care Unit; CLSI, Clinical and Laboratory Standards Institute; MICs, minimum inhibitory concentrations, PBPs, penicillin-binding proteins. respiratory tract, causing respiratory tract diseases such as pneumonia, bronchitis, otitis media and sinusitis. Under certain circumstances, bacteria invade host cells and evade host immunity, causing systemic infections such as bacteremia, sepsis and meningitis. Therefore, the interaction of $S$. pneumoniae with host respiratory tract epithelial cells is an initial step for infection. Many factors that contribute to the colonization and/or invasion of host epithelial cells have been characterized in $S$. pneumoniae. However, it is becoming obvious that 
Table 1. Primers used for amplification of $l y t A$, penicillin and macrolide resistance genes (9).

\begin{tabular}{|c|c|c|}
\hline Gene & Primer & Amplicon \\
\hline \multirow{2}{*}{ lytA } & 5'- CAA CCG TAC AGA ATG AAG CGG-3' & \multirow{2}{*}{295} \\
\hline & 5'-TTA TTC GTG CAA TAC TCG TGCG-3' & \\
\hline \multirow{2}{*}{ pbp1a } & 5'-AGT ATA TCA AGA ACA CTG GCT ACG-3' & \multirow{2}{*}{195} \\
\hline & 5'-GCT TGG AGT GGT TGA GCTA-3' & \\
\hline \multirow{2}{*}{$p b p 2 b$} & 5'-AAA TTG GCA TAT GGA TCT TTTC-3' & \multirow{2}{*}{203} \\
\hline & 5'- TATTCATCTCTGTCGGTTGC-3' & \\
\hline \multirow{2}{*}{$p b p 2 x$} & 5'- AAG TAA CTATGAACCAGGATCAG-3' & \multirow{2}{*}{147} \\
\hline & 5'-CGAAGCATTTGTGTTTGTGT-3' & \\
\hline \multirow{2}{*}{ erm(B) } & 5'- GAAAAGCTACTCAACCAAATA-3' & \multirow{2}{*}{224} \\
\hline & 5'- AGTAACGGTACTTAAATTGTTTAC-3' & \\
\hline \multirow{2}{*}{$\operatorname{mef}(A)$} & 5'- AGTATCATTAATCACTAGTGC-3' & \multirow{2}{*}{294} \\
\hline & 5'-TTCTTCTGGTACTAAAAGTGG-3' & \\
\hline
\end{tabular}

multiple factors are involved in this complex process (Van der Pol, 2009; Gillespie and Balakrishnan, 2002; Ortqvist, 2005).

Pneumococcal infections are treated with penicillin as the first choice drug, and erythromycin is also frequently used. Previously, pneumococci encountered in the community were uniformly susceptible to penicillin. Since the 1960s and 1970s, penicillin resistance has emerged. Macrolide resistance has also increased dramatically during the last decade. However, alarming high frequencies of penicillin and macrolide-resistant pneumococci have been reported, especially in several Asian countries, including Iran (Pallares et al., 2003). There are three known macrolide resistance mechanisms in $S$. pneumoniae. The target site of macrolides in 50S ribosomal subunit can be modified by methylation of the 23S rRNA adenine residue A2058 resulting in resistance to macrolide, lincosamides and streptogramin $B\left(M^{2} S_{B}\right.$ phenotype). This mechanism is mediated by erythromycin ribosome methyltransferase encoded by $\operatorname{erm}(B)$ and to a lesser extent by $\operatorname{erm}(A)$ genes. Macrolide resistance in $S$. pneumoniae may also result from an efflux system leading to the selective efflux of 14- and 15membered macrolides ( $\mathrm{M}$ phenotype) encoded by the $\operatorname{mef}(A)$ gene (Li, 2010; Weber, 2010).

No beta-lactamase activity has been detected in $S$. pneumoniae resistance to beta-lactam antibiotics which is due exclusively to mutations in their natural target, the penicillin-binding proteins (PBPs), which prevent binding and make them indifferent to beta-lactam, that is, decrease their binding affinity with these drugs (Ferroni and Berche, 2001). These proteins are believed to be enzymes that catalyze the terminal stages of murein synthesis and are inhibited by covalent binding with penicillin at their active site. In highly resistant strains, there is a reduction in the capacity to bind to the molecules of antibiotics in at least three of the five existing PBPs: $p b p 1 a, p b p 2 x$ and $p b p 2 b$ (Maurer et al.,
2008).

The aim of this study was to determine the genetic mechanisms and the phenotypic expression of macrolide and penicillin resistance in $S$. pneumoniae strains collected at Intensive Care Unit (ICU) of the University Hospitals of Shiraz, Iran.

\section{MATERIALS AND METHODS}

A total of 70 samples suspected to be $S$. pneumonia were isolated from patients who were admitted at the ICU of Nemazee and Faghihi Hospital, Shiraz, for the period of 2010 to 2011 were studied. Each patient's history sheet was examined in detail and findings were recorded on standard Performa including demographic data. All patients read and singed an 'informed consent' form at the beginning of the study and declared their willingness for the application of their anonymous data for research purpose.

\section{Microbiological cultures}

The pneumococcal isolates were obtained from invasive and noninvasive sites such as blood, nasopharyngeal secretions, tracheal secretions, sputum and bronchoalveolar lavage, of both pediatric and adult patients. All samples were cultured onto $5 \%$ whole sheep blood agar plates and incubated in the presence of $5 \% \mathrm{CO}_{2}$ overnight at $37^{\circ} \mathrm{C}$. The bacteria were identified based on morphological characters, Gram reaction catalase test, bile solubility and susceptibility to optochin. The lytA gene which encodes autolysin was used as target DNA to confirm $S$. pneumoniae strains (Table 1).

\section{Antimicrobial susceptibility test}

The susceptibilities of $S$. pneumoniae were determined by disc diffusion method according to Clinical and Laboratory Standard Institute (CLSI). The following antimicrobial drugs were included in the tests: ampicillin $(10 \mu \mathrm{g})$, chloramphenicol $(30 \mu \mathrm{g})$, amikacin $(30$ $\mu \mathrm{g})$, cefotaxime $(30 \mu \mathrm{g})$, streptomycin $(10 \mu \mathrm{g})$, tetracycline $(30 \mu \mathrm{g})$, gentamicin $(10 \mu \mathrm{g})$, sulfamethoxazole-trimethpprim (1.25 and 23.75 $\mu \mathrm{g})$, nalidixic acid $(30 \mu \mathrm{g})$, erythromycin $(15 \mu \mathrm{g})$, penicillin $(10 \mathrm{U})$, 


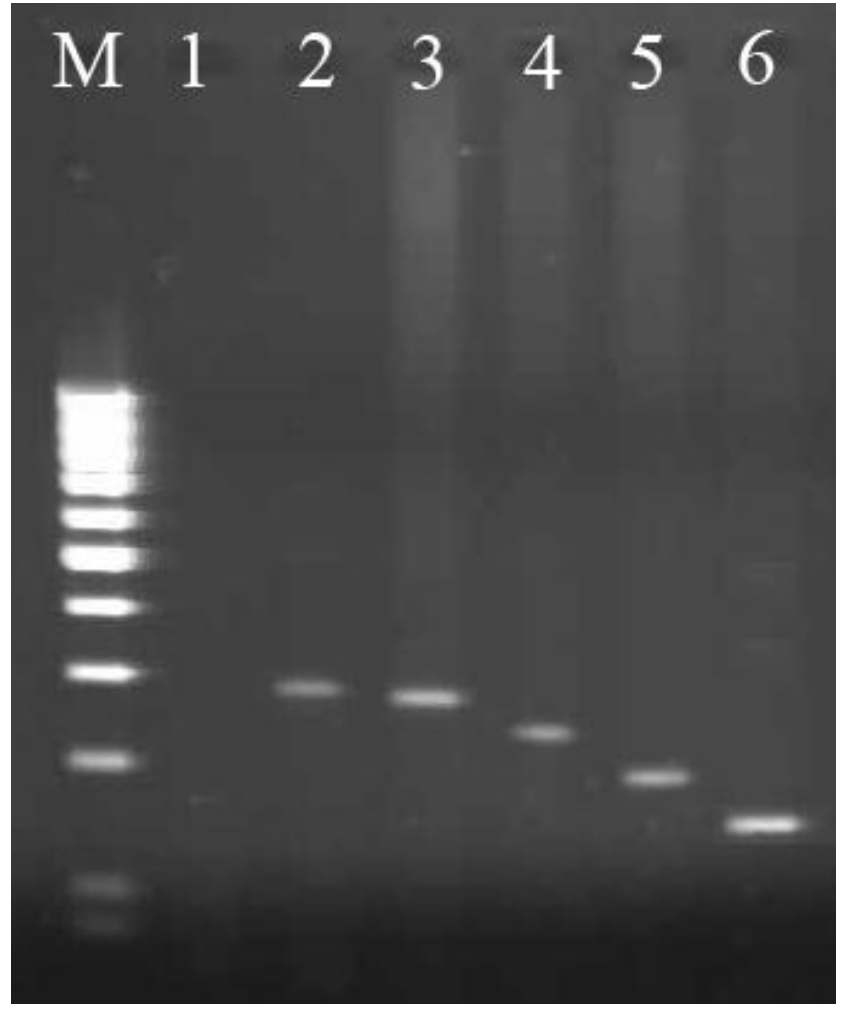

Figure 1. Gel electrophoresis of antibiotic resistance gene in $S$. pneumoniae. M, 100 bp size marker (Fermentase Co., Germany); 1, negative control; 2, 295 bp of lytA gene; 3, 294 bp of mefA gene; 4, 224 bp of ermB gene; 5, 195 bp of pbp1a; 6,147 bp of pbp2x gene.

clarithromycin $(15 \mu \mathrm{g})$, azithromycin $(15 \mu \mathrm{g})$ and levofloxacin $(5 \mu \mathrm{g})$. Minimal inhibitory concentrations (MICs) were determined by the E-test (HiComb, Himedia Co., India) using Muller-Hinton agar (Merck, Germany) supplemented with $5 \%$ whole sheep blood and incubated overnight at $37^{\circ} \mathrm{C}$. MICs values for erythromycin and penicillin were interpreted according to CLSI guidelines. Stringent criteria were adopted for defining multidrug drug resistance (MDR), including resistance to at least four antimicrobial agents.

\section{Conventional PCR}

The DNA extraction was carried out by removing $S$. pneumoniae colonies from the culture medium, resuspending them in $300 \mu \mathrm{l}$ of phosphate-buffer saline and then centrifuging them at $3000 \mathrm{rpm}$ for $15 \mathrm{~min}$. The supernatant was set aside and the sediment was used for DNA extraction. The sediment was re-suspended in $50 \mu \mathrm{l}$ of $1 \mathrm{x}$ Tris-EDTA (TE) buffer at $\mathrm{pH} 7.4$, incubated for $10 \mathrm{~min}$ at $37^{\circ} \mathrm{C}$ and at $100^{\circ} \mathrm{C}$ for $3 \mathrm{~min}$. The samples were stored at $-20^{\circ} \mathrm{C}$ until use (one to three days). The genes that were targeted to identify $S$. pneumoniae were the pneumococcal species specific genes such as the autolysin gene (lytA). Genes that were amplified for detection of penicillin resistance were pbp1a, $p b p 2 b$ and $p b p 2 x$ genes and genes targeting the macrolides genes were the ermB and mefA. The lytA, pbp1a, pbp2b, pbp2x, ermB and mefA genes (Table 1) were amplified by PCR (Figure 1). The optimal PCR condition for a $50 \mu \mathrm{l}$ reaction included $1 \mathrm{X}$ PCR buffer, $1.5 \mathrm{mM} \mathrm{MgCl}_{2}, 0.2 \mathrm{mM}$ dNTP mix, $2 \cup$ Taq Polymerase (Fermentase), 20 pmol of each primer (Table 1) and $10 \mu \mathrm{l}$ of DNA templates (Fukushima et al.,
2008).

PCR amplification was carried with the cycling parameters as follows: after an initial denaturation step at $95^{\circ} \mathrm{C}$ for $5 \mathrm{~min}, 30$ cycles of amplification were performed as follows: denaturation at $94^{\circ} \mathrm{C}$ for $30 \mathrm{~s}$, annealing temperature at $58^{\circ} \mathrm{C}$ for $30 \mathrm{~s}$ and extension temperature at $72^{\circ} \mathrm{C}$ for $30 \mathrm{~s}$. The sizes of PCR products of these genes were analyzed by $1.5 \%$ agarose gel electrophoresis containing ethidium bromide $(0.5 \mathrm{ml})$. The data were analyzed using SPSS software (SPSS for windows, 14 programs) and Chisquare. $\mathrm{P}$-value less than 0.05 were taken to indicate statistical significance.

\section{RESULTS}

The sample consisted of 17 females (24\%) and 53 males $(76 \%)$. The age varied from the newborn to 87 years of age. Of the 70 samples initially identified as $S$. pneumoniae in the microbiology laboratories, eight were excluded from the study for not presenting any growth in culture medium or because the identity of the bacterial species was not confirmed in the microbiological test. The remaining 62 strains were simultaneously submitted to susceptibility tests and PCR to detect erythromycin and penicillin resistance genes and amplification of the IytA gene for confirmation of the bacterial identification. The lyt $A$ gene was detected in 50 samples, and the 12 samples that did not present this gene were removed from the final analysis.

A total of 50 isolates of $S$.pneumoniae were obtained. The major specimen source was sputum (35 isolates), followed by cerebrospinal fluid (CSF, 11 isolates), plural fluid (2 isolates) and blood (2 isolates). There was prevalence of resistant strains to ampicillin (56\%), cefotaxime $(50 \%)$, tetracycline $(10 \%)$, trimethoprim-sulfamethoxazole $(48 \%)$, nalidixic acid $(16 \%)$, erythromycin $(56 \%)$, clarithromycin $(48 \%)$, azithromycin $(44 \%)$, penicillin (60\%) and levofloxacin (4\%). All strain were susceptible to chloramphenicol, amikacin, streptomycin and gentamicin. Overall, $20(40 \%)$ isolates demonstrated an MDR phenotype (resistance to four or more antibiotics). MDR to 4, 5, 6, 7 and 8 antibiotics were 12 , $16,6,4$ and $2 \%$, respectively (Table 2 ).

Within the entire $S$. pneumoniae population $(n=50), 23$ (46\%) were susceptible and $27(54 \%)$ were resistant to erythromycin $(\geq 1 \mu \mathrm{g} / \mathrm{l})$. Gene analysis showed that 29 strains $(58 \%)$ had $\operatorname{mef}(A)$ gene, and 24 strains $(48 \%)$ had the $\operatorname{erm}(B) .17(34 \%)$ had both $\operatorname{mef}(A)$ and $\operatorname{erm}(B)$ gene, while $14(28 \%)$ had neither of them. There was a relation between erythromycin resistance and presence of the erm $(B)$ gene $(p<0.036)$ (Table 3$)$.

Of the 50 isolates, 20 (40\%), $10(20 \%)$ and $20(40 \%)$ strains were respectively susceptible, intermediate and resistance to penicillin. Out of the resistance and intermediate strains, $6(20 \%)$ and 1 (3.33\%) strains harbor mutations in pbp1a and pbp2x genes respectively, but $p b p 2 b$ was not identified in the samples. There was no relation between mutations in pbp1a and pbp2x gene and resistance to penicillin (Table 4 ). 
Table 2. Distribution of antibiotic resistance among S. pneumoniae isolates showing different patterns of drug resistance.

\begin{tabular}{|c|c|}
\hline Antibiotic resistance pattern & Number (\%) \\
\hline$P$ & $1(2)$ \\
\hline TE & $1(2)$ \\
\hline NA & $1(2)$ \\
\hline SXT & $2(4)$ \\
\hline $\mathrm{S}, \mathrm{P}$ & $1(2)$ \\
\hline S, NA & $1(2)$ \\
\hline$N A, P$ & $2(4)$ \\
\hline SXT, P & $1(2)$ \\
\hline E, CLR & $1(2)$ \\
\hline C, CTX & $1(2)$ \\
\hline TE, SXT & $1(2)$ \\
\hline TE, CLR & $1(2)$ \\
\hline$N A, P, E$ & $1(2)$ \\
\hline$C, N A, P$ & $1(2)$ \\
\hline SXT, NA, P & $2(4)$ \\
\hline AM, SXT, E & $1(2)$ \\
\hline AM, E, CLR & $1(2)$ \\
\hline $\mathrm{E}, \mathrm{CLR}, \mathrm{AZM}$ & $2(4)$ \\
\hline AM, CLR, AZM & $1(2)$ \\
\hline SXT, CLR, AZM & $1(2)$ \\
\hline TE, SXT, NA, P & $2(4)$ \\
\hline $\mathrm{E}, \mathrm{P}, \mathrm{CLR}, \mathrm{AZM}$ & $1(2)$ \\
\hline SXT, E, P, AZM & $1(2)$ \\
\hline SXT, E, CLR, AZM & $1(2)$ \\
\hline AM, P, CLR, AZM & $1(2)$ \\
\hline AM, SXT, E, P, CLR & $1(2)$ \\
\hline AM, TE, SXT, NA, P & $1(2)$ \\
\hline AM, E, P, CLR, AZM & $1(2)$ \\
\hline SXT, E, P, CLR, AZM & $4(8)$ \\
\hline TE, SXT, E, CLR, AZM & $1(2)$ \\
\hline AM, SXT, E, P, CLR, AZM & $1(2)$ \\
\hline AM, SXT, NA, P, CLR, AZM & $1(2)$ \\
\hline AM, TE, SXT, E, CLR, AZM & $1(2)$ \\
\hline AM, SXT, NA, E, P, CLR, AZM & $1(2)$ \\
\hline AM, SXT, NA, P, E, CLR, LOM & $1(2)$ \\
\hline AM, SXT, NA, P, E, CLR, AZM, LOM & $1(2)$ \\
\hline Sensitive & $6(12)$ \\
\hline Total & $50(100)$ \\
\hline
\end{tabular}

AM, Amoxicillin; AN, amikacin; AZM, azithromycin; C, chloramphenicol; CLR, clarithromycin; CTX, cefotaxime; E, erythromycin; LOM, levofloxacin; NA, nalidixic acid; P, penicillin; S, streptomycin; SXT, sulfamethoxazole-trimethpprim; TE, tetracycline.

\section{DISCUSSION}

The global emergence of in vitro antimicrobial resistance in $S$. pneumoniae has become a serious clinical concern since the 1980s. During the past two decades, the rate of resistance to penicillin, other betalactams and nonbetalactam agents have been increasing rapidly in many parts of the world. In particular, data on rates of pneumococcal resistance from Asian countries at the end of the 1990s were alarming (Deasy, 2009; Livermore, 2003).

Investigations from other countries have also documented an increase in the prevalence of resistance to penicillin and other agents among pneumococcal strains. Pneumococcal resistance to penicillin has increased significantly in recent years, especially in European countries such as Spain, France and Hungary, where it has reached up to $71 \%$. In some states of the USA, resistance to penicillin has reached $44 \%$, whereas in Asia we can find alarming rates ranging from 70 to $78 \%$ in Hong Kong, South Korea and Taiwan (Lynch and Zhanel, 2010). Our study shows that the incidence of penicillinresistant strains among Iranian clinical isolates is alarmingly high (40\%).

Macrolides are used as an alternative to beta-lactams for treatment of respiratory tract infections, however, recent surveillance data showed an increasing prevalence of macrolide-resistant $S$. pneumoniae in many parts of the world. Recent studies in European countries have shown an overall prevalence of erythromycin resistance of $17.2 \%$, with significant national variability. The highest percentage of erythromycin was observed in France $(58.1 \%)$ and Spain $(57.1 \%)$, followed by Italy $(31.4 \%)$ and Belgium (26.3\%). The highest prevalence of macrolide resistance in pneumococci (47\%) in the USA was seen in East South Central, which includes Kentucky, Tennessee, Alabama and Mississippi (Jenkins, 2008; Reinert, 2005; Camargos, 2006).

However, recent data from some Asian countries on macrolide resistance in pneumococci have far exceeded the prevalence rates of Western countries. Song et al. (2004) showed that $80 \%$ of pneumococcal isolates from Hong Kong were resistant to erythromycin, and $91 \%$ of Taiwanese isolates were fully resistant to erythromycin. In our study, resistance to erythromycin was $18 \%$, which was lower than many Asian countries. Generally, erythromycin resistance in pneumococci results from either modification of the drug-binding site (encoded by erm(B)) or active efflux of the drug (encoded by mefA). The efflux mechanism is predominant in macrolide-resistant pneumococci in North America, whereas ribosomal methylation has been found in $>80 \%$ of erythromycinresistant $S$. pneumoniae isolates in most European countries, except Germany. Ribosomal methylation by the erm(B) was the most common mechanism of erythromycin resistance in China, Taiwan, Sri Lanka and Korea, whereas efflux was more common in erythromycinresistant isolates isolated from Hong Kong, Singapore, Thailand and Malaysia. In most Asian countries except Hong Kong, Malaysia and Singapore, the $\operatorname{erm}(B)$ gene was found in $>50 \%$ of pneumococcal isolates either singly or doubly with the $\operatorname{mef}(A)$ gene (Song et al., 2004).

In this study of 50 isolates, 29 strains $(58 \%)$ carried $\operatorname{mef}(A)$ gene and 24 strains (48\%) possessed erm(B) gene. In our study, we observed that there was a 
Table 3. Comparison between MIC and disk diffusion results of erythromycin in different genotypes of $\operatorname{mef}(A)$ and $\operatorname{erm}(B)$ genes.

\begin{tabular}{lccccccccc}
\hline \multirow{2}{*}{ PCR result } & \multicolumn{4}{c}{ MIC } & \multicolumn{3}{c}{ Disk Diffusion } \\
\cline { 2 - 11 } & $\mathbf{<} \mathbf{0 . 0 1} \boldsymbol{\mu g} / \mathbf{m l}$ & $\mathbf{0 . 0 1} \boldsymbol{\mu g} / \mathbf{m l}$ & $\mathbf{0 . 1} \boldsymbol{\mu \mathbf { g } / \mathbf { m l }}$ & $\mathbf{1} \boldsymbol{\mu g} / \mathbf{m l}$ & $\mathbf{1 0} \boldsymbol{\mu g} / \mathbf{m l}$ & $\mathbf{> 3 0} \boldsymbol{\mu g} / \mathbf{m l}$ & $\mathbf{R}$ & $\mathbf{I}$ & $\mathbf{S}$ \\
\hline mef(A) only & 1 & 5 & 1 & 0 & 4 & 1 & 3 & 3 & 6 \\
erm(B) only & 1 & 0 & 1 & 0 & 5 & 0 & 3 & 2 & 2 \\
mef(A)+erm(B) & 0 & 2 & 2 & 0 & 13 & 0 & 3 & 10 & 4 \\
None & 1 & 3 & 6 & 0 & 2 & 2 & 2 & 2 & 10 \\
\hline
\end{tabular}

R, Resistant; I, intermediate; S, susceptible.

Table 4. Comparison between MIC and disk diffusion results of penicillin in different genotypes of $p b p 1 a, p b p 2 b$ and $p b p 2 x$ genes.

\begin{tabular}{|c|c|c|c|c|c|c|c|c|c|}
\hline \multirow{3}{*}{ PCR result } & \multicolumn{6}{|c|}{ MIC } & \multirow{2}{*}{\multicolumn{3}{|c|}{ Disk Diffusion }} \\
\hline & \multicolumn{2}{|c|}{$\mathrm{s}$} & \multicolumn{2}{|c|}{$\mathrm{I}$} & \multicolumn{2}{|c|}{$\mathbf{R}$} & & & \\
\hline & $<0.001 \mu \mathrm{g} / \mathrm{ml}$ & $0.01 \mu \mathrm{g} / \mathrm{ml}$ & $0.1 \mu \mathrm{g} / \mathrm{ml}$ & $1 \mu \mathrm{g} / \mathrm{ml}$ & $10 \mu \mathrm{g} / \mathrm{ml}$ & $>30 \mu \mathrm{g} / \mathrm{ml}$ & $\mathbf{R}$ & I & $\mathbf{s}$ \\
\hline pbp1a & 0 & 0 & 0 & 2 & 3 & 1 & 5 & 1 & 0 \\
\hline$p b p 2 b$ & 0 & 0 & 0 & 0 & 0 & 0 & 0 & 0 & 0 \\
\hline pbp2x & 0 & 0 & 0 & 0 & 1 & 0 & 1 & 0 & 0 \\
\hline None & 8 & 2 & 5 & 3 & 11 & 4 & 14 & 9 & 20 \\
\hline
\end{tabular}

R, Resistant; I, intermediate; S, susceptible.

correlation between phenotypic (erythromycin resistance) and genotypic (presence of the $\operatorname{erm}(B)$ gene) resistance.

$S$. pneumoniae resistance to beta-lactam antibiotics is due exclusively to mutations in their natural target, the penicillin-binding proteins (PBPs), which prevent binding and make them indifferent to beta-lactam, that is, decrease their binding affinity with these drugs. In highly resistant strains, there is a reduction in the capacity to bind to the molecules of the antibiotics in at least three of the five existing PBPs, pbp1a, pbp2x and $p b p 2 b$. Nagai et al. (2001) evaluated the presence of mutations in the $p b p 2 b$ and $p b p 2 x$ gene of 218 samples of $S$. pneumoniae isolated from children in Japan. Mutations in pbp2x were observed in several strains presenting intermediate resistance to penicillin. Zettler et al. (2004) reported that pbp2x was found in $84 \%$ of samples presenting intermediate resistance to penicillin. We observed that out of the resistance and intermediate strains, $6(20 \%)$ and $1(3.33 \%)$ strains harbor mutations in pbp1a and pbp2x genes, respectively but, $p b p 2 b$ was not identified in the samples. There was no relation between penicillin resistance and mutations in pbp $1 a$ and $p b p 2 x$ genes.

\section{Conclusion}

A very important factor in the treatment of patients with pneumococcal infection is the early introduction of antimicrobial therapeutics, which may be decisive in the evolution and prognosis of the disease. Although a number of therapeutic guidelines recommended are for pneumococcal infections, the local pattern of resistance/ susceptibility must be considered. Data presented in this article and related publications emphasize the desperate need to control the proper use of antibiotics to decrease the selective pressure for this and other organisms. Moreover, development of MDR patterns among $S$. pneumoniae strains indicates that newer antibiotics have to be developed to combat drug-resistant pneumococcal infections. Besides the alteration in the pbps genes, there have been other non-PBP resistance mechanisms that have been reported to alter the other $\beta$-lactam resistance in pneumococci, mutations in the histidin protein kinase $\mathrm{CiaH}$ and any mutations in the glycosyltransferase, CpoA. Another non-PBP resistance determinant that is essential for the complete development of high-level penicillin resistance involves alteration in the murMN operon. The murM and murN proteins control the biosynthesis of branched-stem structured cell wall muropeptides.

\section{ACKNOWLEDGEMENT}

The authors are grateful to the Islamic Azad University, Jahrom Branch, for financial support.

\section{REFERENCES}

Camargos P, Fischer GB, Mocelin H, Dias C, Ruvinsky R (2006). Penicillin resistance and serotyping of $S$. pneumoniae in Latin America. Paed. Res. Rev. 7: 209-214.

Deasy J (2009). Antibiotic resistance: the ongoing challenge for effective drug therapy. JAPPA, 22: 18-22.

Ferroni $A$, Berche $P$ (2001). Alterations to penicillin-binding proteins $1 A$, $2 \mathrm{~B}$ and $2 \mathrm{X}$ amongst penicillin-resistant clinical isolates of Streptococcus pneumoniae serotype $23 \mathrm{~F}$ from the nasopharyngeal 
flora of children. J. Med. Microbiol. 50(9): 828-832.

Fukushima KY, Yanagihara K, Hirakata $Y$, Sugahara K, Morinaga $Y$, Kohno S, Kamihira S (2008). Rapid identification of penicillin and macrolide resistance genes and simultaneous quantification of Streptococcus pneumonia in purulent sputum samples by use of a novel real-time multiplex PCR assay. J. Clin. Microbiol. 46(7): 23842388.

Gillespie SH, Balakrishnan I (2002). Pathogenesis of Pneumococcal infection. J. Med. Microbiol. 49: 1057-1067.

Jenkins SG, Brown SD, Farrel DJ (2008). Trends in antibacterial resistance among Streptococcus pneumoniae isolated in the USA: update from PROTEKT US years 1-4. Ann. Clin. Microbiol. Antimicrob. 7: 1-11.

Li Y, Tomita H, Lv Y, Liu J, Xue F, Zheng B, Ike Y (2010). Molecular characterization of $\operatorname{erm}(B)$ and $\operatorname{mef}(E)$ mediated erythromycin resistance streptococcus pneumoniae in China and complete DNA sequence of Tn2010. J. App. Microb.110: 254-265.

Livermore DM (2003). Bacterial resistance: origins, epidemiology, and impact. CID. 36: 11-23.

Lynch JP, Zhanel GG (2010). Streptococcus pneumoniae: epidemiology and risk factors evolution of antimicrobial resistance and impact of vaccines. Curr. Opin. Plum. 16: 217-225.

Maurer P, Koch B, Zerfa I, Krau J, Linden M, Frere JM, Martel CC, Hakenbeck R (2008). Penicillin binding protein 2x of Streptococcus pneumoniae: three new mutational pathways for remodelling an essential enzyme into a resistance determinant. J. Mol. Biol. 376: 1403-1416.

Nagai K, Shibasaki Y, Hasegawa K, Davies TA, Jacobs MR, Ubukata K, Appelbaum PC (2001). Evaluation of PCR primers to screen for Streptococcus pneumoniae isolated and beta- lactam resistance, and to detect common macrolide resistance determinants. J. Antimicrob. Chemother. 48: 915-918.
Ortqvist A, Hedlund J, Kalin M (2005). Streptococcus pneumoniae: epidemiology, risk factors, and clinical features. Semin. Respir. Crit. Care. Med. 26(6): 563-574.

Pallares R, Fenoll A, Liñares J, The Spanish Pneumococcal infection study Network (2003). The epidemiology of antibiotic resistance in Streptococcus pneumoniae and the clinical relevance of resistance to cephalosporins, macrolides and quinolones. Int. J. Antimicrob. Agents, 22: 15-24.

Reinert RR, Reinert S, Linden M, Cli MY, Al-Lahham A, Appelbaum P (2005). Antimicrobial susceptibility of Streptococcus pneumoniae in eight European countries from 2001 to 2003. Antimicrob. Agents Chemother. 7: 2903-2913.

Song JH, Chang HH, Suh JY, Ko KS, Jung SI, Oh WS, Peck KR, Lee NY, Yang Y, Chongthaleong A, Aswapokee N, Chiu CH, Lalitha MK, Perera J, Yee TT, Kumararasinghe G, Jamal F, Kamarulazaman A Parasakthi N, Van PH, So T, Ng TK, ANSORP Study Group (2004). Macrolide resistance and genotypic characterization of Streptococcus pneumoniae in Asian countries: a study of the Asian network for surveillance of resistant pathogens (ANSORP). J. Antimicrob. Chemother. 53: 457-463.

Van der Pol T, Opal SM (2009). Pathogenesis treatment and prevention of pneumococcal pneumoniae. Lancet. 374(9700): 1543-1556.

Weber FT, Dias C, Costa M (2010). Antimicrobial susceptibility of streptococcus pneumoniae and genotypic characterization of erythromycin resistant strains in Porto Alegre, Brazil. Braz. J. Microb. 41: 1-5.

Zettler EW, Scheibe RM, Dias CAG, Santafe P, Moreira JS, Santos DS, Fritscher CC (2004). Polymerase chain reaction used to detect Streptococcus pneumoniae. J. Bars. Pneumole, 30(6): 521-27. 